\title{
Recommendations of Test of Prostate-specific
Antigen along with Histopathological
Examination for the Prostate Lesions
}

\author{
Pallavi Gedam, Sanjay M Chawhan
}

\begin{abstract}
Introduction: Prostate disease is an important growing health problem, presenting a challenge to urologists, radiologists, and pathologists.

Objectives: The aim of the study is to correlate prostatic-specific antigen test with histopathological examination in prostatic lesions and to recommend combine approach for management of the patients of prostatic lesions.

Materials and Methods: This was a prospective study conducted at the department of pathology in a tertiary care center over 6 months. Data were collected from histopathology record department. The 2002 WHO classification was used to diagnose and classify prostate tumors. Gleason's grading system was used for the cases of adenocarcinoma.

Results: In our study, a total of 119 cases of prostatic lesions were noticed. The lesions diagnosed were benign prostatic hyperplasia (79\% of cases), adenocarcinoma (6\% of cases), prostatic intraepithelial neoplasia ( $4 \%$ of cases), stromal nodules of hyperplasia ( $4 \%$ of cases), and atypical adenomatous hyperplasia ( $4 \%$ of cases). A total of $3 \%$ of cases were inadequate. Majority of prostatic lesions were belonging to the 6th decade followed by the 7th decade. All cases of adenocarcinoma were belonging to the 6 th decade. The test of prostatic-specific antigen was higher (more than $10 \mathrm{ng}$ ) in cases of adenocarcinoma.

Conclusion: The study is conducted to see that combine approach of prostate-specific antigen and histopathological examination is useful for its recommendation, for better management of prostatic lesions in tertiary care center.

KEY WORDS: Benign prostatic hyperplasia, prostatic intraepithelial neoplasia, atypical adenomatous hyperplasia, prostate-specific antigen test, prostate-specific antigen.
\end{abstract}

\section{Introduction}

Inflammation, benign prostatic hyperplasia (BPH), and tumors are important prostatic diseases that cause mortality and morbidity in males. The second most commonly diagnosed cancer is prostatic carcinoma globally and the sixth leading cause of death due to cancer in males. ${ }^{[1]}$ In India, it contributes around $5 \%$ of all male cancers. ${ }^{[2]}$ The most commonly used tools to screen for prostate cancer are prostatespecific antigen (PSA) test, digital rectal examination

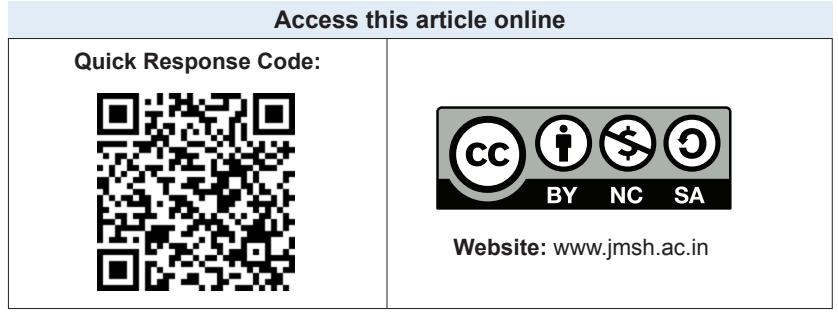

(DRE), and transrectal ultrasound. However, the gold standard for final diagnosis is the proper biopsy. In the clinical practice, the most frequently performed surgical method is transurethral resection of prostate (TURP). The problem lies in the fact that both malignant and benign lesions of the prostate have a very similar clinical presentation, but their management, awareness, prognosis, and follow-up are quite different. The routine DRE may not always be helpful for conclusion. A laboratory investigation that was previously linked to prostatic lesion is prostate-specific antigen (PSA) levels, in which increased levels were thought to be a good indication. ${ }^{[3]}$ However, its significance is only complete when it is supported by histopathological study. Knowing the histological grade in malignant lesions helps in proper management and prognosis. Thus, diagnosis and grading of prostatic lesions are important to both, the clinicians and pathologists.

${ }^{1}$ Assistant Professor, Department of Pathology, Government Medical College, Gondia, Maharashtra, India, ${ }^{2}$ Associate Professor, Department of Pathology, Government Medical College, Gondia, Maharashtra, India Address for correspondence:

Dr. Sanjay M Chawhan, Department of Pathology, Government Medical College, Gondia, Maharashtra, India.

Phone: +91-9823642628. E-mail: chawhansanjay30@gmail.com 


\section{Materials and Methods}

A prospective study was carried out at the department of pathology in a tertiary care center. A total of 119 cases of prostatic lesions were studied during July 2016-December 2016. Data were collected from biopsy and record department. The proper specimens were received and fixed in 10\% formalin. The processed tissue was then stained with routine hematoxylin and eosin staining. All the specimens were analyzed as type of specimen, age of the patient, microscopic features, and diagnosis. The 2002 WHO classification was used to diagnose and classify prostate tumors. Gleason's grading system was used for grading the cases of adenocarcinoma. ${ }^{[3]}$

\begin{tabular}{lc}
$\begin{array}{l}\text { Table 1: Distribution of the number of cases of } \\
\text { prostate lesion by their diagnosis }\end{array}$ \\
\hline Diagnosis & $\begin{array}{c}\text { Number of } \\
\text { cases (\%) }\end{array}$ \\
\hline Benign prostatic hyperplasia (BPH) & $94(79)$ \\
Adenocarcinoma (including s/o & $7(6)$ \\
adenocarcinoma) & $5(4)$ \\
Prostatic intraepithelial neoplasia (PIN) & $5(4)$ \\
Stromal nodules of hyperplasia & $5(4)$ \\
Atypical adenomatous hyperplasia & $3(3)$ \\
Inadequate specimens (repeat biopsy) & $119(100)$ \\
\hline
\end{tabular}

\section{Results}

Table 1 shows that the most common lesions diagnosed was BPH in 94 cases (79\%), followed by seven cases of adenocarcinoma (6\%) and least were five cases of prostatic intraepithelial neoplasia (PIN) (4\%), five cases of stromal nodules of hyperplasia (4\%), and five cases of atypical adenomatous hyperplasia (AAH) (4\%). As per Table 2, majority of prostatic lesions (66) were seen in 51-60 years of age followed by 25 cases in 61-70 years of age. Six cases were noted in $<50$ years and more than 80 years of age, respectively. Fifty-two cases (79\%) of $\mathrm{BPH}$ were seen in the $6^{\text {th }}$ decade (51-60 years) followed by 22 cases $(11 \%)$ in the $7^{\text {th }}$ decade (71-80 years). For adenocarcinoma, all the cases were observed in the $6^{\text {th }}$ decade (51-60 years). Table 3 shows that prostatic-specific antigen (0-4 level) was most common in 66 cases of prostatic lesion (57\%) followed by 4.1-10.0 levels in 33 cases $(29 \%)$. The most frequently seen PSA level was $0-4.0$ in 60 cases (91\%) of BHP followed by $4.0-10.0$ in 26 cases (79\%). In adenocarcinoma, the most common PSA level was $>10.1$ in 4 cases (57\%) followed by $0-4.0$ level in 2 cases (29\%) and 4.0-10.0 level in 1 case (14\%).

BPH on microscopy shows the glandular component made up of nodules of small and large acini lined by basal and secretory cells. Some glands show papillary

Table 2: Distribution of prostatic lesions according to age

\begin{tabular}{|c|c|c|c|c|c|c|}
\hline $\begin{array}{l}\text { Age } \\
\text { group }\end{array}$ & $\begin{array}{c}\text { Benign } \\
\text { prostatic } \\
\text { hyperplasia (\%) }\end{array}$ & $\begin{array}{c}\text { Adenocarcinoma } \\
(\%)\end{array}$ & $\begin{array}{c}\text { Prostatic } \\
\text { intraepithelial } \\
\text { neoplasia (\%) }\end{array}$ & $\begin{array}{c}\text { Stromal } \\
\text { nodules of } \\
\text { hyperplasia (\%) }\end{array}$ & $\begin{array}{c}\text { Atypical } \\
\text { adenomatous } \\
\text { hyperplasia (\%) }\end{array}$ & Total \\
\hline$<50$ & 6 & 0 & 0 & 0 & 0 & 6 \\
\hline $51-60$ & $52(79 \%)$ & 7 (11\%) & $3(4 \%)$ & $2(3 \%)$ & 2 (3\%) & 66 \\
\hline $61-70$ & 22 & 0 & 1 & 1 & 2 & 26 \\
\hline $71-80$ & 10 & 0 & 0 & 1 & 1 & 12 \\
\hline$>81$ & 4 & 0 & 1 & 1 & 0 & 6 \\
\hline Total & 94 & 07 & 05 & 05 & 05 & 116 \\
\hline
\end{tabular}

Table 3: Distribution of prostatic lesion according to prostatic antigen-specific test (PSA)

\begin{tabular}{|c|c|c|c|c|c|c|}
\hline $\begin{array}{l}\text { Prostatic-specific } \\
\text { antigen level } \\
(\mathrm{ng} / \mathrm{ml})\end{array}$ & $\begin{array}{c}\text { Benign } \\
\text { prostatic } \\
\text { hyperplasia (\%) }\end{array}$ & $\begin{array}{c}\text { Adenocarcinoma } \\
(\%)\end{array}$ & $\begin{array}{c}\text { Prostatic } \\
\text { intraepithelial } \\
\text { neoplasia (\%) }\end{array}$ & $\begin{array}{c}\text { Stromal } \\
\text { nodules of } \\
\text { hyperplasia (\%) }\end{array}$ & $\begin{array}{c}\text { Atypical } \\
\text { adenomatous } \\
\text { hyperplasia (\%) }\end{array}$ & Total \\
\hline $0-4.0$ & $60(91)$ & $1(14)$ & 1 & 2 & 1 & 66 (57) \\
\hline $4.1-10.0$ & $26(79)$ & $2(29)$ & 1 & 2 & 2 & $33(28)$ \\
\hline$>10.1$ & $8(50)$ & $4(57)$ & 3 & 1 & 1 & 17 (15) \\
\hline Total & 94 & 07 & 05 & 05 & 05 & 116 \\
\hline
\end{tabular}


infoldings and others are dilated and cystic and show corpora amylacea. Stromal component often shows both fibrous and smooth muscle elements [Figures 1 and 2]. A total of $79(84 \%)$ cases also showed prostatitis. Only $8 \%$ of clinical incidence of BHP is seen during the $4^{\text {th }}$ decade, but it reaches $50 \%$ by the $5^{\text {th }}$ decade and progresses to $75 \%$ in the $8^{\text {th }}$ decade of life.

Adenocarcinoma is the most common type of malignancy in the prostate and the glandular pattern observed under low power microscope is important as it is used for Gleason grading [Figure 3]. ${ }^{[4]}$ The most common score obtained was nine in three cases of a total of six adenocarcinoma cases.

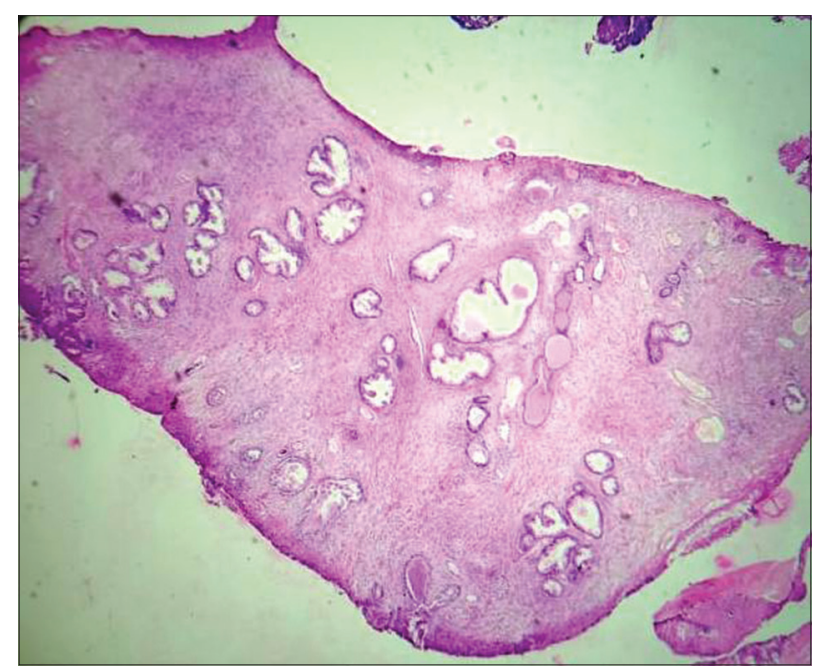

Figure 1: Photomicrograph shows benign prostatic hyperplasia (glandular and stromal component)

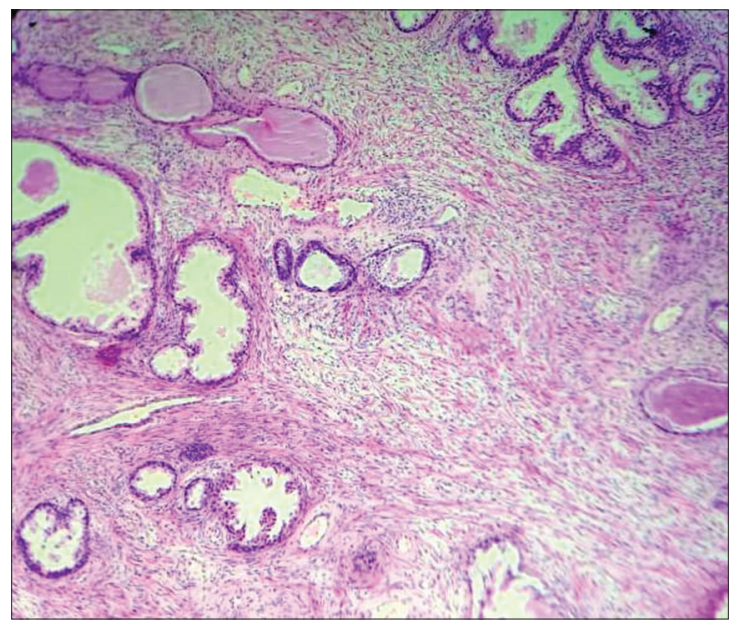

Figure 2: Photomicrograph shows benign prostatic hyperplasia (glandular component made up of nodules of small and large acini lined by basal and secretory cells. Stromal component shows both fibrous and smooth muscle elements)
PIN diagnosis is made when microscopically benign prostatic acini or ducts are lined by cytological atypical cells showing stratification and slight nuclear enlargement. In the current study, a total of five cases of PIN were diagnosed.

Stromal nodules of hyperplasia represent the smallest nodules of $\mathrm{BPH}$ that is often stromal and are composed of loose mesenchymal tissue and prominent small round vessels. Sometimes, TUR of prostate may contain extensive stromal $\mathrm{BPH}$ that can be misdiagnosed with stromal tumors of uncertain malignant potential.

$\mathrm{AAH}$ is a pseudoneoplastic lesion that can be confused with prostate adenocarcinoma due to its morphological features. PIN and AAH were assumed to be precursors of prostatic adenocarcinoma initially; ${ }^{[5]}$ however, PIN now remains as the only well-proven preneoplastic condition with clinical significance. Nowadays, $\mathrm{AAH}$ is not considered a premalignant lesion but seen as a benign small glandular process. A localized proliferation of small acini within the prostate is AAH by definition. Such proliferations may be misdiagnosed as carcinoma. The glands with AAH have a fragmented basal layer. Three cases were inadequate for opinion as only occasional prostatic gland along with stroma was seen microscopically. For such cases, repeat biopsy was advised.

\section{Discussion}

$\mathrm{BPH}$ and adenocarcinoma are two most common conditions affecting prostate gland. In the present

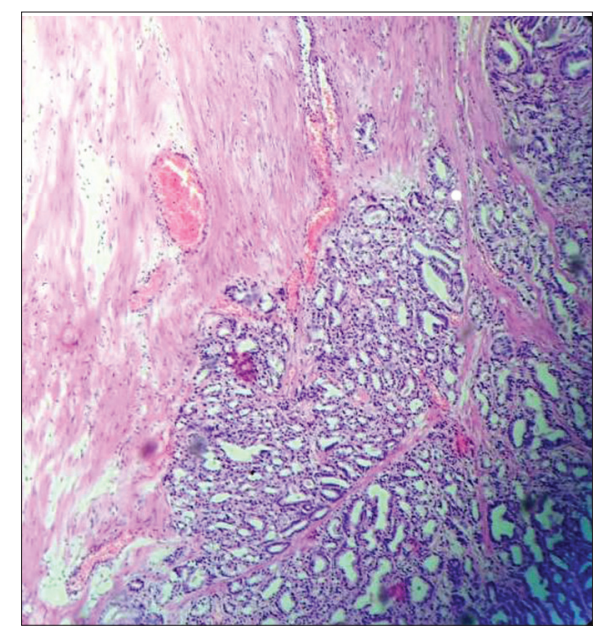

Figure 3: Photomicrograph shows adenocarcinoma prostate (glandular pattern observed under low power) 
study, we had $79 \%$ of cases of BPH, $6 \%$ of cases of adenocarcinoma, $4 \%$ of cases each of PIN, stromal nodules of hyperplasia, and AAH, respectively, and $3 \%$ of cases were inadequate. Similarly, Garg et al. reported that non-neoplastic prostatic tumor cases were of $78 \%$ followed by $21.7 \%$ of cases of adenocarcinoma. ${ }^{[6]}$ Recently, higher incidence of neoplastic lesion was observed due to the diagnosis of prostate carcinoma at an early stage. Moreover, the study was carried out at tertiary health center. According to Ashish and Kaushal et al., majority of prostatic lesions were $61 \%$ of cases of $\mathrm{BPH}$ followed by $25 \%$ of cases of adenocarcinoma and $7 \%$ of case of HGPIN. ${ }^{[7]}$ As per Jasani et al., the most common prostatic lesion was BPH 56\% followed by adenocarcinoma $32 \% .^{[8]}$

In our study, majority of prostatic lesions (66) were seen in 51-60 years of age followed by 25 cases in 61-70 years of age and least six after 80 years of age. This is well known fact that prostate involvement mostly occurs after middle age. Similar study by Jasani et al. reported that the most common age group in prostatic lesions was $5^{\text {th }}$ decade (51\%) followed by the $6^{\text {th }}$ decade $(41 \%) .{ }^{[7]}$ Garg et al. found that mean age in prostatic lesion was 68.6 years. $^{[6]}$

The standard assessment to diagnose prostate cancer is DRE, PSA, and transurethral biopsy. The DRE has constantly been the primary method for evaluating the prostate. It is easy to conduct and cause little anxiety to the patient, but Smith and Catalona showed that the DRE depends on the investigator and has great interexaminer variability. ${ }^{[9]}$ DRE is neither specific nor sensitive enough to identify prostate cancer and is unlikely to be improved. ${ }^{[10]}$

The frequency of the diagnosis of prostate malignancy has increased considerably since the introduction of PSA screening. As per Jasani et al., for diagnosis of $\mathrm{BPH}$, mean PSA level is $4.86 \pm$ 3.03; for adenocarcinoma, mean PSA level is 21.87 \pm 14.7 ; and for PIN, mean PSA level is $9.26 \pm$ $4.34 .{ }^{[7]}$

According to Wolf et al., the PSA and DRE may make false-positive or false-negative results, meaning that men without cancer may have abnormal outcome and get unnecessary additional testing, and clinically, important cancers may be missed..$^{[11]}$ False-positive results can lead to constant anxiety about prostate cancer risk. Abnormal results from screening with the PSA or DRE necessitate prostate biopsies to establish whether or not the abnormal findings are cancer. Biopsies can be painful, may lead to complications such as bleeding or infection, and can miss clinically important cancer. It is not necessary that all men whose prostate cancer is detected through screening require immediate treatment, but they may require periodic blood tests and prostate biopsies to determine the need. In our study, prostatic-specific antigen (0-4 level) 66 (57\%) was the most common in prostatic lesion followed by (4.1-10.0 level) 33 (28\%).

\section{Conclusion}

TURP was the most common type of specimen received for prostatic lesions. The majority of lesions are seen in the $6^{\text {th }}$ decade of life. The most common prostatic lesion observed is $\mathrm{BPH}$ followed by prostatic adenocarcinoma. PIN presents as an important diagnostic challenge as they are known precursor lesions of prostatic carcinoma. PSA should be used for screening purpose, but its significance is only complete when it is supported by histopathological study. The most significant investigation for such cases is the biopsy of the prostate. Histopathological diagnosis and grading plays a definitive role in the proper management and prognosis of prostatic cancer. Hence, it is recommended to use the PSA test along with histopathological examination for prostate lesions, causing decrease in number of cases over the years, thus increasing the life span of males in our country.

\section{References}

1. Dabir PD, Ottosen P, Høyer S, Hamilton-Dutoit S. Comparative analysis of three and two-antibody cocktails to AMACR and basal cell markers for the immunohistochemical diagnosis of prostate carcinoma. Diagn Pathol 2012;7:81.

2. Indian Council of Medical Research. Consolidated Report of Population Based Cancer Registries 2001-2004: Incidence and Distribution of Cancer. Bangalore (India): Coordinating Unit, National Cancer Registry Programme, Indian Council of Medical Research; 2006.

3. Thompson IM, Pauler DK, Goodman PJ, Tangen CM, Lucia MS, Parnes HL, et al. Prevalence of prostate cancer among men with a prostate-specific antigen level $<$ or $=4.0$ ng per milliliter. N Engl J Med 2004;350:2239-46.

4. Epstein JI, Allsbrook WC Jr., Amin MB, Egevad LL, ISUP Grading Committee. The 2005 international society of urological pathology (ISUP) consensus conference on Gleason grading of prostatic carcinoma. Am J Surg Pathol 2005;29:1228-42.

5. Armah HB, Parwani AV. Atypical adenomatous hyperplasia 
(adenosis) of the prostate: A case report with review of the literature. Diagn Pathol 2008;3:1-4.

6. Garg M, Kaur G, Malhotra V, Garg R. Histopathological spectrum of 364 prostatic specimens including immunohistochemistry with special reference to grey zone lesions. Prostate Int 2013;1:146-51.

7. Ashish J, Kaushal CS. The histomorphological study of prostate lesions. J Dent Med Sci 2015;14:85-9.

8. Jasani JH, Patel HB, Geewal B, Vaishnani HV. Diagnostic utility of prostatic specific antigen for detection of prostatic lesion. Int J Biomed Adv Res 2012;3:268-72.

9. Van Der Cruijsen-Koeter IW, Wildhagen MF, De Koning HJ, Schröder FH. The value of current diagnostic tests in prostate cancer screening. Br J Urol Int 2001;88:458-66.

10. Unal D, Sedelaar JP, Aarnink RG, van Leenders GJ, Wijkstra H, Debruyne FM, et al. Three-dimensional contrastenhanced power doppler ultrasonography and conventional examination methods: The value of diagnostic predictors of prostate cancer. BJU Int 2000;86:58-64.

11. Wolf AM, Wender RC, Etzioni RB, Thompson IM, D'Amico AV, Volk RJ, et al. American cancer society guideline for the early detection of prostate cancer: Update 2010. CA Cancer J Clin 2010;60:70-98.

\section{Financial Support: None; Conflict of Interest: None}

How to cite this article: Gedam P, Chawhan SM. Recommendations of Test of Prostate-specific Antigen along with Histopathological Examination for the Prostate Lesions. J Med Sci Health 2019;5(2):28-32.

Date of submission: 03-03-2019

Date of review: 19-07-2019

Date of acceptance: 05-08-2019

Date of publication: 10-10-2019 